\title{
INFLUENCE OF COUPLING AGENTS ON RHEOLOGICAL, THERMAL EXPANSION AND MORPHOLOGICAL PROPERTIES OF RECYCLED POYPROPYLENE WOOD FLOUR COMPOSITES
}

\author{
Matheus Poletto ${ }^{1, \AA}$
}

\begin{abstract}
In this work, thermal expansion and morphological properties of recycled polypropylene wood flour composites were evaluated in order to verify the effect caused by the usage of a natural oil as coupling agent. The natural oil used as coupling agent was octanoic acid (C8), maleic anhydride grafted polypropylene (MAPP), widely used in industry but from non-renewable source, was also used for comparison. Composites were obtained by twin screw extrusion and injection molded. The results showed that the addition of octanoic acid and maleic anhydride grafted polypropylene reduced the coefficient of thermal expansion of the composites. The dependence of melt viscosity obeyed the Arrhenius-Eyring expression, and the activation energy values for composite viscous flow were higher than matrix. The composite morphology revels that octanoic acid promotes strong interfacial adhesion between filler and matrix, similar to that observed when maleic anhydride grafted polypropylene were used. Octanoic acid showed similar results when compared with maleic anhydride grafted polypropylene in all properties evaluated, indicating that can be used as an alternative instead of use coupling agent from non-renewable sources.
\end{abstract}

Keywords: Coefficient of thermal expansion, flow activation energy, melt flow index, natural oil, octanoic acid.

\section{INTRODUCTION}

The search for materials with particular characteristics for specific purposes and at the same time being renewable and environmental friendly is increasing due to a lack of resources and increasing levels of environmental pollution (Nafchi et al. 2015, Kord et al. 2016, Poletto 2017a). Lignocellulosic polymer composites developed with recycled polymers and wood wastes provide an interesting alternative to reduce the consumption of non-renewable resources (AlMaadeed et al. 2014). These composites presents several advantages when compared with mineral-filled polymer composites, such as, low density, reduce health hazard, non-abrasive behavior during processing, renewability and biodegradability (Teuber et al. 2016, Tufan et al. 2016).

Due to such advantages lignocellulosic thermoplastic composite materials are an emerging research and development area and the object of several applications in the automotive, construction and aerospace industries (Naghmouci et al. 2015, Turku et al. 2017). However, the use of lignocellulosic fibers in polymeric composites presents some drawbacks such as degradation at relatively low

\footnotetext{
${ }^{1}$ Programa de Pós-Graduação em Engenharia de Processos e Tecnologias (PGEPROTEC), Universidade de Caxias do Sul (UCS), Caxias do Sul, Rio Grande do Sul, Brazil.

"Corresponding author: mpolett1@ucs.br

Received: 26.12.2017 Accepted: 01.05.2018
} 
temperatures and low compatibility between the hydrophilic character of the polar lignocellulosic filler and hydrophobic character of the non-polar polymer matrix (Khonsari et al. 2015, Poletto 2017b).

Several methods are adopted to treat either the surface of the fiber or the polymer matrix in order to enhance the adhesion and ensure an acceptable load transfer (El-Sabbagh 2014) improving the composite mechanical properties. A physical modification includes treatments by heat, plasma, corona, and surface fibrillation; while chemical treatments includes different methods (El-Sabbagh 2014), such as alkalinisation, acrylation, acetylation, sinalisation, among others.

Maleic anhydride-grafted thermoplastic polymers, such as maleic anhydride grafted polypropylene, are the most common coupling agent used to improve the interfacial adhesion between lignocellulosic fillers and a thermoplastic polymer matrix (Yuan et al. 2008, Poletto et al. 2012, Fonseca-Valero et al. 2015). The advantage of use maleic anhydride-grafted thermoplastic polymers is that type of coupling agent can be used directly with the available compounding machine without inserting a new processing step to the production cycle (El-Sabbagh 2014). An issue, however, arises from the fact that maleic anhydride-grafted thermoplastic polymers come from non renewable sources and based on the current environmental concerns new fonts of coupling agents may be explored.

In a recent work, Martins and Santana (2016) used three different carboxylic acids, myristic (C14), palmitic $(\mathrm{C} 16)$ and stearic acids $(\mathrm{C} 18)$ as natural compatibilizer agents in thermoplastic starch and polypropylene blends. The authors observed an increase in the mechanical properties evaluated due the better compatibility between the immiscible blend components promoted by the carboxylic acid incorporation. In another study, Spoljaric et al. (2009) also observed an increase in mechanical properties when stearic acid was used as coupling agent in polypropylene cellulose composites. Freire et al. (2008) developed low-density polyethylene cellulose composites with cellulose fibers treated with hexanoic (C6), dodecanoic (C12), octadecanoic (C18) and docosanoic (C22) acids. The chemical modification of cellulose fibers with fatty acids improved the interfacial adhesion with the polymer matrix and also improved the composite mechanical properties. The carboxylic acids may be a renewable source of coupling agents for composite materials. Octanoic acid, for example, is naturally found in coconut oil, palm kernel oil and milk of ruminants and human (Wang et al. 2018, Sanap et al. 2015).

So, the aim of this work was to compare the influence of two coupling agents, one from a renewable octanoic acid (C8) and another from a non-renewable source maleic anhydride grafted polypropylene (MAPP) on the morphology, thermal expansion, melt flow index (MFI) and flow activation energy of recycled polypropylene wood flour composites.

\section{Theoretical Background}

The flow process mechanism of polymers can be elucidated by a study of the temperature dependence of shear viscosity (Shenoy et al. 1983, Shenoy 1999). The Arrhenius-Eyring equation is used to express the temperature dependence of shear viscosity, as can be seen in Equation 1:

$$
n=A_{0} e^{E_{a} / R T}
$$

where $\eta$ is the viscosity at temperature $T, R$ is the gas constant, $A_{0}$ is the frequency term depending on the entropy of activation for flow (Shenoy et al. 1983, Shenoy 1999) and $\mathrm{E}_{\mathrm{a}}$ is taken to be the energy of activation for viscous flow.

Saini and Shenoy (1983) used a modified Arrhenius-Eyring type equation for activation energy of flow through viscosity measurements, especially for zero shear viscosity, using melt flow index (MFI) for estimating flow activation energy (Saini and Shenoy 1983). The advantage of this method is based on the fact that MFI is an easily determinable parameter in comparison to the zero shear viscosity (Shenoy 1999). The modified form of Arrhenius type equation is written as presented in Equation 2: 


$$
M F I=B e^{E_{a} / R T}
$$

where $\mathrm{E}_{\mathrm{a}}$ can be calculated from the slope of $\log$ MFI versus 1/T plot, $\mathrm{B}$ is a constant, $\mathrm{R}$ is the gas constant $8,3 \mathrm{~J} \mathrm{~mol}^{-1} \mathrm{~K}^{-1}$ and $\mathrm{T}$ is the temperature in $\mathrm{K}$.

\section{MATERIALS AND METHODS}

\section{Materials}

Recycled polypropylene (PP) from post consumer food packaging was supplied by Associação dos Recicladores de Caxias do Sul (Caxias do Sul, Rio Grande do Sul/Brazil) with MFI = 4,6 $\pm 0,2 \mathrm{~g}$ $10 \mathrm{~min}^{-1}$. Wood flour from Pinus elliottii (PIE) was obtained from Madarco Co. (Caxias do Sul, Rio Grande do Sul/Brazil) with particle size between 50-150 $\mu \mathrm{m}$, with average particle size of $100 \mu \mathrm{m}$. The sample was dried in a vacuum oven at $105^{\circ} \mathrm{C}$ for $24 \mathrm{~h}$ before use in composite formulations. Two coupling agents were used. Polybond 3200 (MAPP) supplied by Chemtura Co. Ltd with MFI 10,1 $\mathrm{g} / 10 \mathrm{~min}$ and $\mathrm{C} 8$ also called caprylic acid supplied by Vetec Chemistry. $2 \mathrm{wt} \%$ of each coupling agent was added in composite formulations.

\section{Composite preparation}

Composites with $30 \mathrm{wt} \%$ of wood flour were prepared using a MH-equipments co-rotating twinscrew extruder with $\mathrm{L} / \mathrm{D}=32$ and $\mathrm{D}=20 \mathrm{~mm}$. The screw speed was $200 \mathrm{rpm}$, and operating temperatures were maintained at $170^{\circ} \mathrm{C}-190^{\circ} \mathrm{C}$. The extruded material was previously dried at $105^{\circ} \mathrm{C}$ for $24 \mathrm{~h}$. Specimens were injection molded in HIMACO LH 150-80 equipment at a barrel temperature of 170$180^{\circ} \mathrm{C}$ and mold temperature of $40 \pm 2^{\circ} \mathrm{C}$.

\section{Thermalexpansion}

The coefficient of thermal expansion for pure PP and PP/wood composites was determined from $23^{\circ} \mathrm{C}$ to $120^{\circ} \mathrm{C}$ using a SHIMADZU TMA 60 analyzer at a heating rate of $10^{\circ} \mathrm{C} \mathrm{min}^{-1}$ at a loading of $5 \mathrm{~g}$. Ultra-high-purity nitrogen was used at a constant flow rate of $50 \mathrm{ml} \mathrm{min}^{-1}$. Specimens with dimensions of $8 \times 8 \times 3,2 \mathrm{~mm}$ were used. The systematic error associated with the determination of coefficient of thermal expansion was $5 \%$.

\section{Morphological analysis}

Scanning electron microscopy (SEM) was used to evaluate the cryo-fracture surface of treated and non-treated composites using a SHIMADZU Superscan SS-550 scanning electron microscope at $15 \mathrm{kV}$. Prior to the analysis, the specimens were coated with gold to eliminate the electron charging.

\section{Melt flow index measurements (MFI)}

The MFI tests were carried out in a MFI Kayeness model D4001HV, according to ASTM D1238. Studies were done at 180,200 and $220^{\circ} \mathrm{C}$ with a load of $2.16 \mathrm{~kg}$, in triplicate. 


\section{RESULTS AND DISCUSSIONS}

Dimensional stability is critical for composites in different applications. Poor dimensional stability causes warping and other changes in shape during service (Cheng et al. 2009). The coefficient of thermal expansion (CTE) is a parameter used to evaluate the thermal stability of several materials (Singh and Mohanty, 2007, Cheng et al. 2009, Lebrun and Denault, 2010). Table 1 presents the CTE values for PP and PP/wood flour composites. The wood flour addition reduces the CTE of the composites since the wood fibers imposes a restriction to polymer chain movement. It is also observed that at $30^{\circ} \mathrm{C}$ the reduction in $\mathrm{CTE}$ is more pronounced for compatibilised composites when compared to composites without coupling agent. When the temperature increases, the composite treated with C8 presents a higher thermal expansion than composite compatibilised with MAPP. This behavior is probably influenced by the higher movement of the lower molecular weight chain segments in C8 when compared with the higher molecular weight of the MAPP.

Table 1. CTE of PP and PP/wood flour composites.

\begin{tabular}{|c|c|c|}
\hline Sample & \multicolumn{2}{|c|}{$\mathrm{CTE}\left(10^{-6} /{ }^{\circ} \mathrm{C}\right)$} \\
\hline & $30{ }^{\circ} \mathrm{C}$ & $40-80{ }^{\circ} \mathrm{C}$ \\
\hline PP & 45 & 142,7 \\
\hline PP/PIE & 27,7 & 91,3 \\
\hline PP/PIE/C8 & 11,9 & 107,6 \\
\hline PP/PIE/MAPP & 24,1 & 81,6 \\
\hline
\end{tabular}

Figure 1 shows the SEM micrographs of the fracture surfaces of the non-treated composite and the composites treated with MAPP. The fracture surface of non-treated composite in Figure 1(a) indicated the presence of pulled-out traces and bigger gaps between the wood flour and matrix, which is evidence of weak interfacial adhesion at the interface (Hong et al. 2014, Poletto 2017b). The addition of MAPP promotes better compatibility between the hydrophobic matrix and hydrophilic fiber, as can be seen in Figure 1(b).



Figure 1. SEM micrographs for composites without (a) and with MAPP (b).

The SEM micrograph of the composite treated with C8, Figure 2 (a), shown that the fibers were covered by the matrix. This result demonstrates that the $\mathrm{C} 8$ treatment provides strong interfacial adhesion, probably due the formation of hydrogen bonds between wood and C8 and entanglements between matrix and the non-polar part of C8, as represented in Figure 2 (b). 

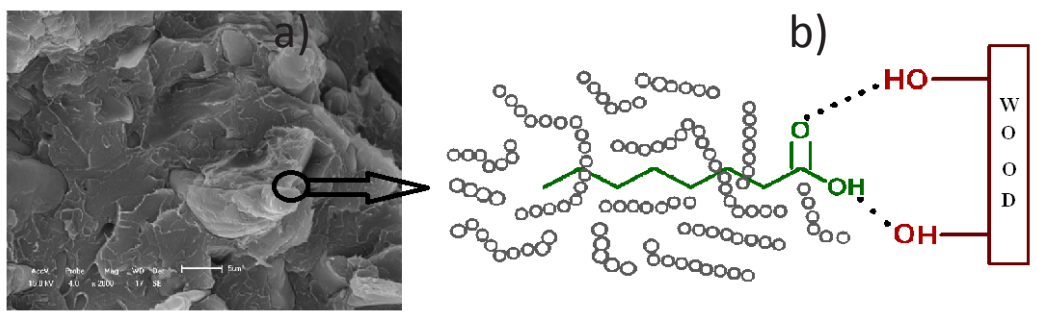

Figure 2. SEM micrograph of (a) composite with C8 and (b) hypothetical model of interactions between wood, $\mathrm{C} 8$ and matrix (0).

The effect of wood flour and coupling agent type used in composite formulations on the MFI values at different temperatures are shown in Figure 3. Wood flour drastically reduces the MFI of the composites when compared with polymer matrix. The MFI decreases and in consequence the viscosity of the composites increases due to the inhibition of the polymer chain motion imposed by the filler particles (Muksing et al. 2008). On the other hand, the presence of $30 \mathrm{wt} \%$ of wood flour into the polymer matrix increases the probability of particle-particle contact and may lead to an increase in viscosity (Huang and Zhang. 2008). The use of MAPP into the composite increases the MFI when compared with composite without coupling agent. The MAPP seems to be acting as a lubricant. The MAPP may tend to increase the intermolecular free volume between polymer chains an act as an internal lubricant, reducing the composite viscosity. In addition, this behavior may be also associated with the migration of an unreacted quantity of MAPP towards to the composite surface creating a slip in the composite layers near to the die which may cause an increase in the MFI. Similar results were observed by Hristov and Vlachopoulos (2007) in natural fiber composites. The addition of C8 results in the lowest MFI value for the composites studied. C8 promotes an improved in the interfacial adhesion, as observed in Figure 2(a), which provides more entanglements between polymer matrix and filler increasing the melt viscosity.

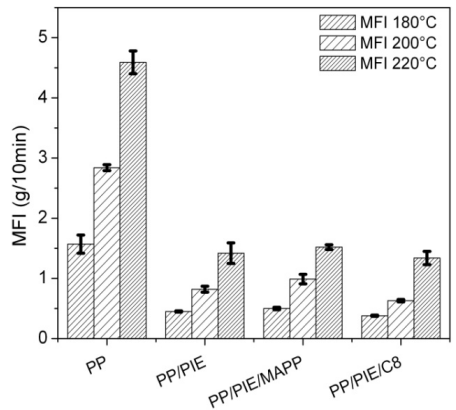

Figure 3: MFI of the samples studied at different temperatures.

The effect of temperature on the viscosity of polymers and composites is an important parameter since these materials undergo considerable temperature changes during processing (Nair et al. 2000). Generally, the composite viscosity decreases when temperature increases (Nair et al. 2000, Hristov and Vlachopoulos 2007). Probably the molecular motion is accelerated at high temperatures due to the greater free volume and also due to the decreasing entanglement density and weaker intermolecular interactions (Nair et al. 2000, Hristov and Vlachopoulos 2007). The flow activation energy (Ea) values, presented in Table 2, were calculated from the angular coefficient obtained from the straight line fit shown in Figure 4. 


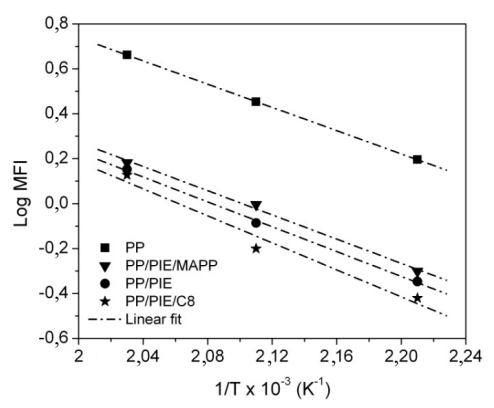

Figure 4. Plot of log MFI vs. 1/T for PP/wood flour composites.

The $\mathrm{E}_{\mathrm{a}}$ increases for composites when compared with the polymer matrix. This may be indicated that composite melt viscosity of the composite is greater affected by the wood particles. The wood flour restricts the material flow and more energy is required for that the composite can flow through the matrix resulting in an increase in $\mathrm{E}_{\mathrm{a}}$ values.

Table 2. $\mathrm{E}_{\mathrm{a}}$ for viscous flow of PP/wood flour composites.

\begin{tabular}{|l|c|c|}
\hline Sample & $\mathrm{E}_{\mathrm{a}}(\mathrm{kJ} / \mathrm{mol})$ & $\mathrm{R}^{2}$ \\
\hline $\mathrm{PP}$ & 21,6 & 0,999 \\
\hline $\mathrm{PPr} / \mathrm{PIE}$ & 23,2 & 0,999 \\
\hline $\mathrm{PPr} / \mathrm{PIE} / \mathrm{C} 8$ & 25,3 & 0,981 \\
\hline PPr/PIE/MAPP & 22,5 & 0,989 \\
\hline
\end{tabular}

MAPP reduces the $\mathrm{E}_{\mathrm{a}}$ of the composite when compared with the sample without coupling agent. MAPP tend to increase the intermolecular free volume between polymer chains an may promote slippage of the polymer chains which results in lower energy to initiate the viscous flow. On the other hand, the composite development with $\mathrm{C} 8$ showed the highest $\mathrm{E}_{\mathrm{a}}$. Probably, $\mathrm{C} 8$ provide an improvement on the adhesion between filler and matrix which may causes more restrictions to the material flow increasing the melt viscosity and the flow activation energy values, in agreement with the morphology observed in Figure 2.

\section{CONCLUSIONS}

The usage of a coupling agent from a renewable source in recycled polypropylene wood flour composites has been studied. The results showed that the addition of $\mathrm{C} 8$ promotes better adhesion between wood flour and polymer matrix, similar to that observed when MAPP were used. The dimensional stability of the composites treated with octanoic acid is higher than composites treated with MAPP at temperatures lower than $30^{\circ} \mathrm{C}$. In addition, the composites compatibilised with $\mathrm{C} 8$ showed the lower MFI and higher flow activation energy than composites treated with MAPP that indicate that higher intermolecular forces are responsible for the better adhesion observed when C8 was used. In general, for the properties evaluated the usage of octanoic acid as a coupling agent in recycled polypropylene wood flour composites showed a similar behavior than the MAPP. 


\section{ACKNOWLEDGEMENTS}

The author is grateful to Associação dos Recicladores Serrano de Caxias do Sul, Madarco S.A. and Chemtura Company for supplying materials.

\section{REFERENCES}

AIMaadeed, M.A.; Nógellová, Z.; Mičušík, M.; Novák, I.; Kruppa, I. 2014. Mechanical, sorption an adhesive properties of composites based on low density polyethylene filled with date palm wood power. Materials and Design 53: 29-37.

Cheng, S.; Lau, K.; Liu, T.; Zhao, Y.; Lam, P.M.; Yin Y. 2009. Mechanical and thermal properties of chicken feather fiber/PLA green composites. Composites Part B 40: 650-654.

El-Sabbagh, A. 2014. Effect of coupling agent on natural fibre/polypropylene composites on mechanical and thermal behaviour. Composites Part B 57: 126-135.

Fonseca-Valero, C.; Ochoa-Mendoza, A.; Arranz-Andrés, J.; González-Sánches, C. 2015. Mechanical Recycling and composition effects on the properties and structure of hardwood cellulosereinforced high density polyethylene eco-composites. Composites Part A 69:94-104.

Freire, C.S.R.; Silvestre, A.J.D.; Pascoal Neto, C.; Gandini, A.; Martin L.; Mondragon, I. 2008. Composites based on acylated cellulose fibers and low-density polyethylene: effect of the fiber content, degree of substitution and fatty acid chain length on final properties. Composites Science and Technology 68: 3358-3364.

Hong, H.; Liao, H.; Zhang, H.; He, H.; Liu, T.; Jia, D. 2014. Significant improvement in performance of recycled polyethylene/wood flour composites by synergistic compatibilization at multiscale. Composites Part A 64: 90-98.

Hristov, V.; Vlachopoulos, J. 2007. Influence of coupling agents on melt flow behavior of natural fiber composites. Macromolecular Materials and Engineering 292: 608-619.

Huang, H. X.; Zhang, J.J. 2009. Effects of filler-filler and polymer-filler interactions on rheological and mechanical properties of HDPE-wood composites. Journal of Applied Polymer Science 111: 28062812.

Khonsari, A.; Taghiyari, H.R.; Karimi, A.; Tajvidi, M. 2015. Study on the effect of wood flour geometry on physical and mechanical properties of wood-plastic composites. Maderas- Cienc Tecnol 17: 545-558.

Kord, B.; Malekian, B.; Yousefi, H.; Najafi, A. 2016. Preparation and characterization of nanofibrillated cellulose/poly (vinylalcohol) composite films. Maderas-Cienc Tecnol 18: 743-752.

Lebrun, G.; Denault, J. 2010. Effect of annealing on the thermal expansion and residual stresses of bidirectional thermoplastic composite laminates. Composite Part A 41: 101-107.

Martins, A.B.; Santana, R.M.C. 2016. Effect of carboxilic acids as compatibilizer agent on mechanical properties of thermoplastic starch and polypropylene blends. Carbohydrate Polymers 135: 79-85.

Muksing, N.; Nithitanakul, M.; Grady, B.P.; Magaraphan, R. 2008. Melt rheology and extrudate swell of organobentonite filled polypropylene nanocomposites. Polymer Testing 27: 470-479.

Nafchi, H.R.; Abdouss, M.; Najaf, S.K.; Gargari, R.M.; Mazhar, M. 2015. Effects of nanoclay particles and oxidized polypropylene polymers on improvement of the thermal properties of wood 
plastic composite. Maderas-Cienc Tecnol 17: 45-54.

Naghmouci, I.; Espinach, F.X.; Mutjé, P.; Boufi, S. 2015. Polypropylene composites based on lignocellulosic fillers: how the filler morphology affects the composite properties. Materials and Design 65: 454-461.

Nair, K.C.M.; Kumar, R.P.; Thomas, S.; Schit, S.C.; Ramamurthy, K. 2000. Rheological behavior of short sisal fiber-reinforced polystyrene composites, Composite Part A 31: 1231-1240.

Poletto, M.; Zeni, M.; Zattera, A.J. 2012. Effects of wood flour addition and coupling agent content on mechanical properties of recycled polystyrene/wood flour composites. Journal of Thermoplastic Composite Materials 25: 821-833.

Poletto, M. 2017a. Mechanical, dynamic mechanical and morphological properties of composites based on recycled polystyrene filled with wood flour wastes. Maderas-Cienc Tecnol 19: 433-442.

Poletto, M. 2017b. Polypropylene-based wood-plastic composites: effect of using a coupling agent derived from a renewable source. Maderas-Cienc Tecnol 19: 265-272.

Saini, D.R.; Shenoy, A.V. 1983. A new method for the determination of flow activation energy of polymer melt. Journal of Macromolecular Science. Part B 22: 437-449.

Sanap, D.P.; Kadam, K.D.; Narayan, M.; Kasthurirangan, S.; Nemade, P.R.; Dalvi, V.H. 2015. Analysis of saline water desalination by directed solvent extraction using octanoic acid. Desalination 357: $150-162$.

Shenoy, A.V.; Saini, D.R.; Nadkarni, V.M. 1983. Rheograms for engineering thermoplastics from melt flow index. Rheologica Acta 22: 209-222.

Shenoy, A.V. 1999. Rheology of filled polymer systems. Kluwer Academic Publishers: The Netherlands.

Singh, S.; Mohanty, A.K. 2007. Wood fiber reinforced bacterial bioplastic composite: fabrication and performance evaluation. Composite Science and Technology 67: 1753-1763.

Spoljaric, S.; Genovese, A.; Shanks, R.A. 2009. Polypropylene-microcrystalline cellulose composites with enhanced compatibility and properties. Composites Part A 40: 791-799.

Teuber, L.; Osburg, V.S.; Toporowski, W.; Militz, H.; Krause, A. 2016. Wood polymer composites and their contribution to cascading utilization. Journal of Cleaner Production 110: 9-15.

Tufan, M.; Akbaş, S.; Aslan, M. 2016. Decay resistance, thermal degradation, tensile and flexural properties of sisal carbon hybrid composites. Maderas-Cienc Tecnol 18: 509-606.

Turku, I.; Keskisaari, A.; Kärki, T.; Puurtinen, A.; Marttila, P. 2017. Characterization of wood plastic composites manufactured from recycled plastic blends. Composite Structures 161: 469-476.

Wang, Q.; Lei, J.; Ma, J.; Yuan, G.; Sun, H. 2018. Effect of chitosan-carvacrol coating on the quality of Pacific white shrimp during iced storage as affected by caprylic acid. International Journal of Biological Macromolecules 106: 123-129.

Yuan, Q.; Wu, D.; Gotama, J.; Bateman S. 2008. Wood fiber reinforced polyethylene and polypropylene composites with high modulus and impact strength. Journal of Thermoplastic Composite Materials 21:195-208. 